\title{
Investigation of thermogenic gas generation by on-line open-system pyrolysis-GC-IRMS
}

PHILIPP WENIGER ${ }^{1 *}$, MARTIN BLUMENBERG ${ }^{1}$, STEFAN SCHLÖMER $^{1}$, BERNHARD M. KROOSS ${ }^{2}$

${ }^{1}$ Federal Institute for Geosciences and Natural Resources

(BGR), Hannover, Germany (* philipp.weniger@bgr.de)

${ }^{2}$ Energy and Mineral Resources Group (EMR), RWTH

Aachen University, Germany

The stable carbon isotope composition of thermogenic gas is inherited from the isotope composition of source rock kerogen and kinetic isotope fractionation associated with thermal decomposition of kerogen precursor compounds. Integration of molecular and stable carbon isotope composition is an established tool in petroleum geochemistry for interpretation of genetic origin, source rock organic matter type, degree of thermal maturity and for source-gas correlation $[1,2]$.

To improve understanding of thermogenic gas generation, we performed laboratory pyrolysis experiments of different source rocks using open system pyrolysis-GC-IRMS at different heating rates $(0.2$ to $5 \mathrm{~K} / \mathrm{min})$ following previous work by Gaschnitz et al. [3]. Results showed expected ${ }^{13} \mathrm{C}$ enrichment in gaseous products with increasing maturity, but also revealed variations that reflect differences in precursor strucutres of different kerogens. The experimental data can be used to derive isotope-specific reaction kinetic parameters for basin and petroleum systems modelling.

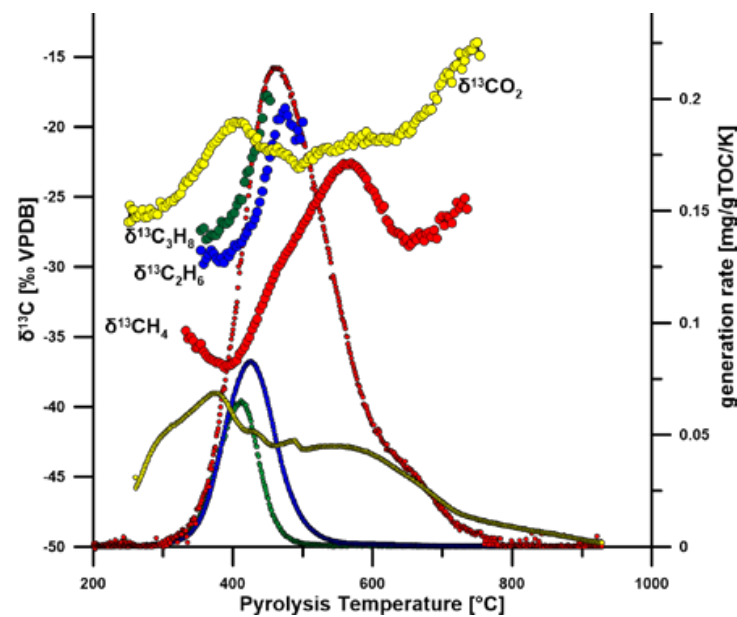

Figure 1: Pyrolytic gas generation (coal, $0.2 \mathrm{~K} / \mathrm{min}$ ).

[1] Fuex (1977) JGE 7, 155-188. [2] Schoell (1983) AAPG Bull. 67, 2225-2238. [3] Gaschnitz et al. (2001) Fuel 80, 2139-2153. 